Mantell Building, University of Sussex, Brighton BN1 9RF, UK

$\dagger$ Department of Epidemiology and Public Health, University College London, London WC1E 6BT, UK $\ddagger$ GeneWatch UK, The Courtyard, Whitecross Road, Tideswell, Buxton, Derbyshire SK17 8NY, UK

1. Millstone, E., Brunner, E. \& Mayer, S. Nature 401, 525-526 (1999).

2. Trewavas, A. \& Leaver, C. J. Nature 401, 640 (1999).

3. Food \& Agriculture Organization/World Health Organization Biotechnology and Food Safety: Report of a Joint FAO/WHO Consultation (FAO, Rome, 1997).

4. Gasson, M. J. Nature 402, 229 (1999).

5. Getz, J. M., Venecil, W. K. \& Hill, N. S. The 1999 Brighton Conference 8C-6, 835-840 (British Crop Protection Council, Farnham, 1999).

6. Burke, D. Nature 401, 640-641 (1999).

\section{Why Diamond should go to Daresbury}

Sir - You report that the Wellcome Trust favours siting the new Anglo-French synchrotron source (Diamond) at the Rutherford Appleton Laboratory in southern England instead of at Daresbury Laboratory near Manchester (Nature 402, $451 ; 1999)$. I am concerned about Wellcome's statement that it is important to site Diamond close to the existing neutron spallation source (ISIS).

In fact, no protein-crystallography research is done on ISIS. Neutron proteincrystallography research is and will be conducted at the Institut Laue Langevin neutron source in Grenoble, France. I hold a Wellcome Trust research grant to work on both synchrotron X-ray proteincrystallography data collection and neutron protein-crystallography data collection. It has not been necessary to have $\mathrm{X}$-ray and neutron sources at the same location - it is simply not a requirement.

I am surprised that I have not been asked my opinion by anyone on the question of the siting of Diamond. Not only am I the chairman of the Institut Laue Langevin neutron beam-time biology review committee, but I have also chaired synchrotron $\mathrm{X}$-ray advisory committees for the European synchrotron radiation facility in France, Cornell in the United States and the Daresbury Synchrotron Radiation Source protein-crystallography beam panel.

I strongly support Daresbury as the site of Diamond. This vital project requires the vast body of experience among the staff at Daresbury Laboratory. The Rutherford Appleton Laboratory has its own expertise and is planning its own ISIS neutron source upgrades. But this is irrelevant to placing Diamond in the best UK location for its optimal, proper and successful development, which should be at Daresbury.

Finally, I warmly welcome the Wellcome Trust's involvement to the fullest extent possible in Diamond at Daresbury. The protein-crystallography programme on Diamond must be as vibrant as possible, given the importance of structural biology in the expanding fields of structure-based drug design and health care. The trust and the UK government research agencies are key players in this enterprise that should ensure the continuing international competitiveness of UK research and its pharmaceutical industry.

\section{John R. Helliwell}

Department of Chemistry, University of Manchester, Manchester M13 9PL, UK

\section{Seeking a guide to the quality of web writing}

Sir - The Opinion article "Dangers of over-dependence on peer-reviewed publication" presents an interesting perspective on an important debate (Nature 401, 727; 1999). It refers to a study on the problem of 'defining a publication' carried out by an international ad-hoc group under our joint chairmanship at the request of the science, technical and medical publishers, and presented to their recent meeting in Frankfurt. Far from blurring the concept of a publication, our proposals attempt to impose some order on the continuum of publication that has become possible in the electronic environment.

We acknowledge the variety of forms of scientific writing found on the Internet, and offer criteria for distinguishing among them, thereby giving readers a clearer basis than now exists for evaluating the status and credibility of whatever they are reading. We invite your readers to examine our discussion document (at the website http://associnst.ox.ac.uk/ icsuinfo/ aaas-stm.htm) and to contribute to the refinement or rebuttal of these ideas. Roger Elliott ${ }^{\star}$, Mark S. Frankel $\dagger$ ${ }^{*}$ Chairman, ICSU Press, Department of Theoretical Physics, University of Oxford, 1 Keble Road, Oxford OX1 3NP, UK $\dagger$ American Association for the Advancement of Science, 1200 New York Avenue NW, Washington DC 20005, USA

\section{How ethical principles can aid research}

Sir - Søren Holm and John Harris argue that the precautionary principle stifles discovery (Nature 400, 398; 1999). I believe such a judgement to rely on a misunderstanding of the link between science and progress.

Discovery is by definition never selfevident: when a problem arises, the most apparently ready-made ways to solve it are likely to be the least productive in genuine novelty. This is precisely where moral issues come in, in science as in life in general. Real progress originates from the refusal to take a path that would threaten one's own moral choices and values. It is in such a situation, which to me is the essence of science as a daughter of ethics, that other ways do show up, not previously thought of, which lead to discovery. It is precisely the moral problem coming to the researcher's consciousness that alerts him to the fact that he is able to find another way. Not listening to the voice of consciousness in such a situation thus leads to missed discoveries. Therefore it is precisely in research that ethical principles are most useful.

So the precautionary principle should be viewed rather as a guide to avoid wrong directions, opening the way to better ones. Joël Sternheimer

Reseau Associatif de Chercheurs Independants, 1 rue Descartes, 75005 Paris, France

\section{Lobbying groups must be trustworthy}

Sir- I agree with H. Mohr that Greenpeace has no credibility when it comes to evaluating science (Nature 401, $524 ; 1999)$. Many of its activities and campaigns are based on propaganda rather than facts.

Academic research requires freedom from commercial competition and dependence. Mohr says he has enjoyed such freedom all his life, but this begs the question of whether this freedom is likely to be reduced if commercial interests arise. In cases where scientific results are open to different interpretations, scientists should not have a monopoly on opinion and answers, particularly on issues of public importance. Organizations representing the general public must have a say.

But these organizations must be trustworthy, rather than manipulating facts to suit their own agendas. People usually trust relief organizations, such as the Red Cross or Médecins sans Frontières, but these organizations generally avoid controversial issues. There are, however, numerous local organizations that are concerned with science in respect of both the environment and the production of food and other consumer goods. One example is Bellona in Oslo, recognized for its work with nuclear waste in the former Soviet Union. We need more of these types of organization at the international level, assuming they use acceptable methods.

Ketil Haarstad

Jordforsk, Norwegian Centre for Soil and Environmental Research, $\mathrm{N}-1432$ Ås, Norway 